\title{
Aplicación Temporal de la Ley Penal, Validez y Eficacia en Infracciones de Agresión al Estado
}

\author{
Temporary Application of Criminal Law, Validity and \\ Effectiveness in Aggressions to the State
}

\section{Renata Melissa Yunda López}

Investigadora Jurídica, Blue Wave Ybstelcom S.A.

Artículo Original (Revisión)

RFJ, No. 3, 2018, pp. 119-142, ISSN 2588-0837

RESUMEN: el siguiente artículo tiene por objeto el estudio y análisis del ámbito de aplicación de la ley en materia penal, este es uno de los cuatro efectos de la ley penal, además, se proyecta en el espacio, en el tiempo, en las personas y en la materia. "La temporalidad se refiere al tiempo, y cuando se relaciona lo temporal con la ley es sinónimo de vigencia" (Rosillo, 2017, 12). Una de las principales razones para proceder con esta investigación es brindar información certera acerca de la validez y la eficacia de la aplicación temporal de la ley penal, sobre todo a profesionales entendidos de la materia, para ello se utilizará distintos métodos de investigación que permitirán analizar y recolectar información referente al tema. Respecto al ámbito de aplicación temporal de la ley penal encontramos que la sucesión de las leyes penales plantea algunos problemas en cuanto a su eficacia temporal, uno de ellos es el de las leyes temporales que son emitidas para un período o una situación específica, pierde automáticamente o por derecho su vigencia. Pero, qué pasa cuando se aplica esta ley; si en materia penal se imputa a hechos punibles que tengan lugar solo después de su vigencia, uno de los errores que se comete es aplicar el principio de retroactividad de la ley penal más favorable al acusado. Tema que más adelante se extenderá y mostrará los motivos que inciden a cometer este tipo de errores. Además, se interpretará el Art. 16 Título V del Código Orgánico Integral Penal, referente al ámbito de aplicación temporal, de manera clara y concisa, logrando tener mayor entendimiento sobre cuando, a quienes y en qué momento debe ser aplicada. 
PALABRAS CLAVES: ley, temporalidad, eficacia, validez, vigencia de la ley, infracción, principio de legalidad.

ABSTRACT: the article aims to study and analyze the scope of application of the law in criminal matters, this is one of the four effects of criminal law, in addition, it is projected in space, in time, in people and in the matter. "Temporality refers to time, and when the temporal is related to the law it is synonymous with validity" (Rosillo, 2017, page 12). One of the main reasons for proceeding with this investigation is to provide accurate information about the validity and effectiveness of the temporary application of the criminal law, especially to knowledgeable professionals, for this purpose different research methods will be used that will allow analyze and collect information regarding the subject. Regarding the temporal scope of the criminal law we find that the succession of criminal laws poses some problems in terms of its temporary effectiveness, one of which is that of temporary laws that are issued for a specific period or situation, automatically loses or by right its validity. But, what happens when this law is applied; if in criminal matters it is attributed to punishable acts that take place only after its validity, one of the errors committed is to apply the principle of retroactivity of the criminal law more favorable to the accused. Theme that will later be extended and will show the reasons that affect to commit this type of errors. In addition, Article 16 Title V of the Comprehensive Criminal Organic Code, referring to the scope of temporary application, will be interpreted in a clear and concise manner, achieving greater understanding of when, to whom and at what time it should be applied.

KEY WORDS: law, temporality, efficacy, validity, effectiveness of the law, infringement, principle of legality.

\section{INTRODUCCIÓN}

El Derecho debe tener un poder fácticamente efectivo, Jurgen Habermas dice que si el Derecho quiere ser efectivo "debe ser válido, legítimo, sin que con ello se agoten los requisitos de legitimación”. Habermas, sostiene que existe una tensión interna entre eficacia y validez; sin embargo, la eficacia del Derecho no se desplaza esencialmente respecto de la concepción que su existencia pertenece a la esencia

40 Habermans, J. (2009). Facticidad y validez: sobre el derecho y el estado democrático de derecho, Universidad Johann Wolfgang Goethe. 240. 
del Derecho. Es de suma importancia decisiva que las leyes coactivas deban acreditar su legitimidad, con leyes libertarias en el proceso y solamente por el tipo de proceso que establece la ley.

Para que una norma jurídica sea válida, debe ser creada por un acto que es un hecho existente en el tiempo y el espacio. Un orden jurídico considerado como un todo, y las normas jurídicas que lo constituyen, se consideran válidas, si son obedecidas y aplicadas en todos los ámbitos, es decir, si posee eficacia. Pero no debemos confundir su validez con su eficacia, la validez quiere decir que la ley debe ser obedecida y aplicada; la eficacia se refiere a que de verdad está siendo obedecida y aplicada, por ello se entiende "41 "que la eficacia es solamente una condición de la validez, no es igual a ella”.

La ley por carácter general surte efecto únicamente durante su vigencia, lo que se traduce en la irretroactividad de la ley como principio general. Pero existen excepciones a esta regla de la ley penal en el tiempo, que permiten su retroactividad; principio del que se hablará en profundidad más adelante, y por ende su aplicación a un caso determinado que sucede mientras esta ley aún no estaba vigente.

Como ya se ha mencionado anteriormente, es de aplicación la ley vigente en el momento de comisión del hecho punible, al ser esta una regla que se deriva del principio de legalidad. Esto quiere decir que las leyes penales solo alcanzan a los hechos cometidos después de su entrada en vigencia.

El Código Orgánico Integral Penal ecuatoriano, recoge este principio en su artículo 16 numeral 2 según el cual42 "se aplicará la ley penal posterior más benigna sin necesidad de petición, de preferencia sobre la ley penal vigente al tiempo de ser cometida la infracción o dictarse sentencia". En concordancia con lo establecido la ${ }^{43}$ "ley es obligatoria desde el día siguiente de su publicación en el Registro Oficial, salvo disposición contraria de la misma que posterga su vigencia en todo o en parte".

Los efectos de la ley en el tiempo, establecen cuestiones relativas

41 Kelsen, H. (2005). Validez y Eficacia del Derecho, Editorial Astrea, 49-50.

42 Código Organico Integral Penal, Registro Oficial 180 del $1^{\circ}$ de julio de 1895 , Última Edición 10 de febrero de 2014.

43 Constitución de la República del Ecuador, Registro Oficial 449 del 20 de octubre del 2008, Artículo 137, Párrafo 3. 
a su vigencia: el momento en que inicia su vigencia y cuando esta termina. Surgen problemas de $\operatorname{conflictos}^{44}$ entre leyes que provocan preguntas técnicas, para resolver aquello es necesario el establecimiento de alguna regla de segundo orden que establezcan criterios para determinar que leyes se deben aplicar (la anterior o la posterior; la nacional o la internacional).

Estos conflictos surgen porque las relaciones jurídicas con frecuencia no son instantáneas, más bien se prolongan a lo largo del tiempo, esta materia es regulada por algunos principios que se encuentran recogidos en el Código Civil ecuatoriano y por normas específicas establecidas en la ley sobre efecto retroactivo de las leyes. Respecto a la Vigencia de la ley existen dos principios a los que se debe regir: vigencia inmediata de la ley e irretroactividad de la ley. Las leyes penales, en principio, no tienen efecto retroactivo como lo establece el Código Civil45", "La ley no dispone sino para lo venidero: no tiene efecto retroactivo", cabe recalcar que en el inciso 22 literal (a) expresa "Lo que una ley posterior declara absolutamente imprescriptible no podrá ganarse por tiempo, bajo el imperio de la nueva ley, aunque el prescribiente hubiere principiado a poseer conforme a la ley anterior que autorizaba la prescripción", esto quiere que decir ningún delito se castigará con otra pena que la que señale una ley promulgada con anterioridad a su perpetración.

El principio de legalidad penal es el fundamento de la irretroactividad de las leyes penales. Como dicen Cobo Del Rosal y Vives Antón, ${ }^{46}$ “... generalmente, las razones que se han ofrecido para justificar la irretroactividad de la ley penal vienen girando en torno a los criterios que dimanan del régimen de garantías, que no sería otra cosa, sino concreción del principio de legalidad...", se refiere a que , el principio de legalidad, sintetizado en la conocida máxima nullum crimen nulla poena sine lege praevia, atribuida a Feuerbach y que ${ }^{47}$ da lugar a las lla-

44 Barros, E. (1995). Vigencia de la ley. Efectos de la ley en el tiempo, Universidad de Chile. 1.

45 Código Civil Ecuatoriano, Registro Oficial N 46 del 10 de mayo del 2005, Artículo 7, párrafo 3.

46 Cobo Del Rosal, V.A. (1999). Comentario al art. 2 del Código Penal, en Comentarios al Código Penal (Dir. por Manuel Cobo del Rosal, Ed. Edersa, Madri), I. 72.

47 La apreciación de estas características se suele atribuir a Maurach. Tratado de Derecho Penal (trad. por Córdoba Roda, Barcelona, 1962), I, 8, V, A. 100. Citado por Urzúa, C. (1996). Derecho Penal. Parte General (2a edición, tomo I, Santiago de Chile). 143. 
madas garantías del principio de legalidad, criminal, penal, y de ejecución comporta que para que la ley cumpla dichas garantías, debe reunir ciertas características, como ser anterior al delito (lex praevia), escrita $^{48}$, lo que excluye la costumbre como fuente directa de Derecho Penal (lex scripta) y formulada con precisión, lo que excluye la aplicación de la analogía - prohibición dirigida al juez penal- e impone el respeto del principio de taxatividad o mandato de determinación -exigencia destinada al legislador- (lex stricta).

Así en la doctrina, tradicionalmente, se ha exigido la irretroactividad de la ley penal (lex praevia) cuando se explica el contenido del principio de legalidad.

\section{PRINCIPIO DE IRRETROACTIVIDAD DE LA LEY}

La irretroactividad de las leyes penales y el principio de vigencia temporal, son elementos que deben estar en constante coordinación. En ambos casos la ley no puede regular ni aplicarse sino únicamente aquellos hechos cometidos bajo su período de vigencia temporal (tempus regit actum). Este principio se refiere a que está prohibido aplicar una ley desfavorable a hechos ocurridos con anterioridad a su entrada en vigor, al mismo tiempo establece que los efectos de una ley perjudicial, cesan cuando han terminado su imperio, sea porque en una sucesión de leyes se contempla la situación más afable o porque se deja de contemplar.

Existen dos tipos de vigencia temporal para las leyes penales: vigencia formal, es el tiempo que media entre la entrada en vigor de la ley y su derogación y vigencia material, que se aplica exclusivamente a los hechos ocurridos bajo su imperio, la prohibición de retroactividad ${ }^{49}$

48 Así, en lo que respecta a la lex stricta y su contenido: Mourullo, R. (1971). Principio de legalidad, en Nueva Enciclopedia Jurídica (Barcelona), XIV. 888; PUIG, M., Derecho Penal. Parte General. 78; Mourullo, R. (1995). Introducción a las bases del Derecho Penal. 145. Sin embargo, hay quienes derivan el mandato de determinación de la exigencia de una lex certa (exigencia hecha por Jescheck; véase Cury Urzúa, Derecho Penal. Parte General. 144), reservando la noción de lex stricta para la prohibición de aplicación de la analogía. García-Pablos, Derecho Penal. Introducción (Madrid). 248; Hassemer, Fundamentos del Derecho Penal. 314 y ss.; Zugaldia

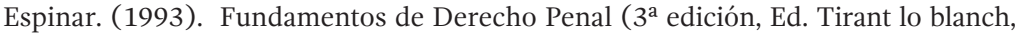
Valencia. 281.

Ruiz, L. (2011). El Principio de Irretroactividad de la Ley Penal en la Doctrina y la 
significa que al impedir que se aplique la ley desfavorable alcanza no solamente a los hechos que han tenido lugar con anterioridad desde su entrada en vigor, sino también a las consecuencias o situaciones que tienen lugar bajo su vigencia, pero han sido generadas previamente por la ley anterior más benigna. ${ }^{50}$

La exigencia de la prohibición de retroactividad únicamente se acatan si la totalidad de los presupuestos fundamentadores del delito o de la pena fueron realizados bajo el período de vigencia de la ley posterior más estricto, exactamente lo opuesto es la aplicación de la ley más benigna: no es necesario que ningún presupuesto del delito o de la pena tenga lugar bajo su vigencia para poder tomarla en consideración en el caso que suceda a otra más gravosa. ${ }^{51}$

La extensión que debe darse al principio de irretroactividad de la ley penal, alcanza a todo hecho o circunstancia cuya toma en consideración da lugar a la aplicación, con carácter retroactivo, de una disposición sancionada desfavorable o restrictiva de Derechos individuales. De esta manera la irretroactividad comprende, bajo esta premisa, cualquier presupuesto que vaya a ser tomado en cuenta en la declaratoria de culpabilidad y que contribuya a fundamentar desfavorablemente un delito o una falta.

Las mismas consideraciones deben hacerse para las leyes penales en sentido estricto: sin perjuicio de la cuestión de fondo o forma que plantean. ${ }^{52}$

\subsection{Retroactividad de la ley}

La palabra "retroactividad", deriva del latín, significa "retro agüere" accionar, hacia atrás, obrar hacía atrás. De acuerdo con las fuentes romanas se acude a varias expresiones: "retroagitur", "reducitur" o "res retroducitur" y activus, que produce efectos y por tanto significa

Jurisprudencia, Derecho Penal, Universidad de Extremadura. 153- 154.

50 Ruiz, C., en comentarios, II. 39, Mourullo, R., Derecho Penal. 126.

51 Cobo del Rosal, M. y Vives Antón. (1986). Derecho Penal. 141, Admiten los principio de irretroactividad desfavorable y retroactividad favorable.

52 Sobre su posible inconstitucionalidad, por no respetar la garantía de reserva de ley. Cobo del Rosal, M. y Boix Reig. (1982). Garantías Constitucionales del Derecho Sancionador, Madrid. 
actuar sobre el pasado. ${ }^{53}$ Suárez Collía, la define "en una sucesión temporal de leyes, la aplicación de la norma jurídica nueva, a supuestos de hecho, actos, relaciones y/o situaciones jurídicas nacidas o constituidas con anterioridad a su entrada en vigor y que tuvieron su origen bajo el imperio de otra norma derogada". ${ }^{54}$

La no aplicación de la retroactividad de la ley, se relaciona con el principio de legalidad y la seguridad Jurídica, ${ }^{55}$ elementos fundamentales del Estado de Derecho que garantizan a las personas el conocimiento del alcance de su libertad, así como los límites del poder punitivo del Estado.

Su prohibición en perjuicio de persona alguna forma parte del derecho a la estricta aplicación, que no solo forma parte en materia penal, sino también le corresponde a la legislación civil.

Como ya se ha visto, este principio tiene gran relevancia en materia penal, ya que se refiere a toda norma que pueda afectar un derecho humano o adquirido, Javier Dondé, señala que el principio de legalidad en materia penal se integra por la no aplicación de la retroactividad de la ley ${ }^{56}$, es decir, solo aplica la norma que está en vigor cuando los hechos punibles se cometieron.

Esta prohibición también es conocida en el ámbito internacional, en aquellos casos que involucran conflictos armados, cabe señalar que la no aplicación de la retroactividad, no es imputable cuando la norma favorece a la persona, por ejemplo cuando se suprime un delito y se reducen las sanciones o bien se reconocen nuevas causas de justificación..$^{57}$

53 Verdera Izquierdo, B. (2006). La irretroactividad: Problemática general. Editorial Dykinson. Madrid. 11.

54 Suárez Collía, JM. (2005). La retroactividad: Normas jurídicas retroactivas e irretroactivas. Edita Centro de Estudios Ramón Areces. Madrid. 11.

55 Aranda, D. (2003). Derecho Penal, Parte general (conceptos, principios y fundamentos del Derecho Penal mexicano, conforme a la teoría del delito funcionalista social), UNAM, México. 68.

56 Donde, J. (2010). Principio de Legalidad Penal. Perspectivas del Derecho Nacional e Internacional, México: Porrúa. 109.

57 Maier, J. (2003). Derecho Procesal II, Parte General. Sujetos Procesales, Buenos Aires, Editores del Puerto. 79. 
Un acto es retroactivo cuando obra sobre el tiempo pasado, por lo tanto una ley es retroactiva cuando obra en tiempo pasado, siempre y cuando rijan situaciones existentes con anterioridad a su vigencia.

Para Moto Salazar, la retroactividad puede ser retroactividad negativa o positiva ${ }^{58}$; es negativa cuando no permite su aplicación en perjuicio de persona alguna, y la positiva es aquella que está permitida en su aplicación y viene a constituir una obligación para el juez competente, por ser la que más beneficia al inculpado.

La aplicación del principio de retroactividad o irretroactividad de las normas debe llevar a una solución equilibrada, no hermética, objetiva y acorde con la realidad que se vive en cada momento, al ponderar todas las circunstancias y los intereses en cada caso.

En materia penal rige el principio que la nueva ley no afectará al demandado, pero puede ser aplicada en el tiempo hacia atrás, en caso que esa norma lo beneficie. ${ }^{59}$ Así lo establece la Declaración Universal de los Derechos Humanos en su artículo 11 inciso 2. Sin embargo, existen excepciones a la irretroactividad de las leyes como ocurre en el caso de los delitos de lesa humanidad.

Para Carlos D., "por el principio de seguridad jurídica se encuentra vedada la aplicación retroactiva de la ley penal más gravosa...en cuyo caso debe aplicarse la ley penal sustantiva vigente al momento de cometer el ilícito...". ${ }^{60}$ Este precepto afirma que la seguridad jurídica es uno de los elementos más afectados como consecuencia de la retroactividad de la ley.

\subsection{Principio de Legalidad}

El principio de legalidad es formulado bajo el aforismo que se le atribuye a Feuerbach, nullum crimen, nulla poena sine lege, quiere decir, no hay delito ni pena sin una ley que lo sancione, una ley que debe ser previa a la comisión del hecho delictivo y una ley que debe serlo tam-

58 Saavedra, J. (1994). Aplicación Retroactiva de la Ley Penal, Anuncio Jurídico. Nueva Serie. 304.

59 Declaración Universal de los Derechos Humanos, Registro Oficial 10 de diciembre de 1948, Resolución 217, Artículo 11 inciso 2. 2015.

60 Carlos, D. (2012). Retroactividad e Irretroactividad, Los tiempos. 7. 
bién en sentido formal, esto es, una norma emanada de la Asamblea como órgano de la representación política.

La legalidad no es, sin embargo, un concepto reciente; al margen de precedentes más o menos remotos, ${ }^{61}$ cabe considerar al principio de legalidad como un "hijo de la Ilustración" que surge en los orígenes ideológicos del Derecho Penal moderno como la primera consecuencia del fundamento contractual del ius puniendi, pero también, y al mismo tiempo, como el primero de sus límites.

El principio de legalidad debe ser también entendido como expresión del principio democrático-representativo. ${ }^{62}$ Desde esta perspectiva, el principio de legalidad no solo debe garantizar el imperio de la ley frente al activismo judicial y exigir la previa tipificación de las conductas delictivas sino que, además, debe asegurar que el contenido de la ley constituye una expresión de la voluntad general.

El principio de legalidad, con el significado que tan solo el Poder Legislativo es el que puede decidir lo que resulta punible, al establecer los preceptos primario - descripción típica-y secundaria-sanción penal-, tiene como fuente principal de inspiración la doctrina de la separación de los poderes de Montesquieu ${ }^{63}$. Desde entonces, se hizo definitivamente inadmisible, particularmente en materia penal, en virtud de sus derechos, reflejos con relación a importantes derechos humanos fundamentales ${ }^{64}$, el Poder Ejecutivo asume la tarea de definir delitos y describir penas, puesto que cuida de legítima y exclusiva función del Legislador, que es el único representante del pueblo, autorizado para ello.

Para respetar el principio de legalidad no basta tan solo editar una norma. Hay que sujetarse a todas sus exigencias. Si se tratase únicamente de editar un texto normativo, se podría concluir que el Presidente de la República puede legislar en materia penal por medida

61 Lamarca, C. (2012). Principio de Legalidad Penal, Eunomía. Revista en Cultura de la Legalidad. Universidad Carlos III de Madrid. 157.

62 Arroyo, L. (1983). El Principio de Determinación del Hecho Punible en la Doctrina del Tribunal Constitucional, Madrid. 18.

63 Montesquieu. (1992). O espírito das leis, trad. de Pedro Vieira Mota, 2a ed., São Paulo: Saravia, especialmente "Libro Décimo Primeiro". 161.

64 Gómes, L. (2001). El Principio de Legalidad y sus Garantías Mínimas: Una Contribución al Estudio de la Garantía de la "Lex Populi”, Universidad de Castilla- La Mancha. 1028. 
provisional; además, se podría decir que hasta el legislador (mediante la ley) puede elaborar una norma retroactiva o imprecisa, hasta permitir analogía contra el reo $^{65}$. Sin embargo, en un Estado que asume el modelo liberal del Estado de Derecho, está vedado.

El principio de legalidad fue concebido como barrera de contención, y punto límite a la corrupción de los gobiernos y a su vez como garantía de los ciudadanos contra el exceso, desproporción y abuso del arbitraje del Estado ${ }^{66}$, al hacer uso del poder punitivo.

De allí que, nadie pueda verse obligado a aquello que la ley no ordene. Además, la legalidad se entronizó como garantía de la igualdad y la seguridad jurídica debido a que la ley al incorporar un mandato abstracto, universal e impersonal, se dirige a todos los miembros de la sociedad; esto permite que el delito y su sanción sea igual para todos, sin distinción que diversos estamentos sociales (nobleza, milicia y clero), cuando estaba en manos del monarca definir lo que es delito y su castigo; así mismo, el tener reglas claras le permite al sujeto prever las consecuencias de sus actos y amoldar su conducta dentro de su ámbito de libertad individual.

El principio de legalidad natural, se entiende como la ley que rige el acontecimiento, el acontecimiento se sujeta a la ley, y jamás se espera que el acontecimiento viole la ley, ${ }^{67}$ seria antinatural. Ahora bien, en el mundo del Derecho no existe tal metáfora, debido a que la relación de causalidad que hay en el mundo natural no existe en el Derecho. Lo que hay en el mundo jurídico es una relación de imputación, una conexión entre el acto y la consecuencia, ${ }^{68}$ porque el mundo del Derecho es un deber ser.

Rolando Tamayo y Salmorán, conciben el principio de legalidad como:

(...) el principio de legalidad es presupuesto en todo discurso jurídico, tanto en la "descripción" (textos y tratados) como en la

65 Cobo del Rosal, T. y Vives Antón, M. Estado-de-Derecho..., en Comentarios a la Legislación Penal, t. I/11.

66 Ulloa, A. (2013). Principio de Legalidad y Derecho Penal Contemporáneo, Revista de Derecho, Ecuador, Párrafo 4.

67 Islas Montes, R., (2009). Sobre el Principio de Legalidad, Anuario de Derecho Constitucional latinoamericano. 100.

68 Kelsen, H. (2007). Teoría para el derecho, México. 96. 
argumentación (alegatos). El principio opera en dos niveles: descriptivo y justificativo. El tenor del principio podría formularse así: (1) es regla de competencia; i, e., es el derecho de un Estado (...) todo acto jurídico (orden, decisión, mandato) supone una norma jurídica que confiere facultades; todo poder o facultad requiere necesariamente de fundamentación jurídica. (2) La legalidad debe controlar los actos de los funcionarios (e, g., el exceso o desvío de poder, decisión ultra vires, son cuestiones jurídicas). ${ }^{69}$

Con lo expuesto en el párrafo anterior, el principio de legalidad se opone a los actos que estén en contraste con la ley, a los actos no autorizados por la ley y aquellos que no están regulados completamente por la ley. Este principio demanda la unión de todos los órganos estatales de Derecho, en otras palabras; todo acto o procedimiento jurídico llevado a cabo por las autoridades debe tener apoyo estricto en una norma legal, la que, a su vez, debe estar conforme a las disposiciones de fondo y forma recogidas en la Constitución.

Estado de Derecho se traduce en la certeza que la autoridad estatal solo podrá actuar con fundamento en algún precepto legal. Por el contrario, un individuo podrá hacer todo aquello que la ley no le prohíba. Esto es lo que también se conoce como principio de legalidad. Hans Kelsen, lo explicó con claridad: Un individuo que no funciona como órgano del Estado puede hacer todo aquello que no está prohibido por el orden jurídico, en tanto que el Estado, esto es, el individuo que obra como órgano estatal, solamente puede hacer lo que el orden jurídico le autoriza a realizar. ${ }^{70}$

Así es expresado el principio de legalidad en su aspecto meramente formal. Para el profesor español FRANCISCO LAPORTA, este aspecto del principio de legalidad es un "universo ético", es decir, "no es una propiedad del Derecho, algo inherente a la mera existencia empírica del orden jurídico, algo que nace ya con la mera norma jurídica, sino que es un postulado metajurídico, una exigencia ético-política o un complejo principio moral que está más allá del puro derecho positivo, o dicho en términos familiares, que no se refiere al derecho que es, sino al derecho que debe ser". ${ }^{71}$

69 Tamayo, R., y Salmorán. (2015). Los publicistas medievales y la formación de la tradición política de occidente, México, UNAM. 214.

70 Kelsen, H. (1995). Teoría general del Derecho y del Estado. 227.

71 Laporta, F. (1994). Imperio de la ley. Reflexiones sobre un punto de partida de Elías 
Además, existe un grado de legalidad superlativo: la constitucionalidad o superlegalidad. Tamayo y Salmorán, mencionan que "es claro percatarse que el principio de constitucionalidad, no es sino un caso especial de legalidad.

Establece la competencia y el control, la conformidad del ejercicio de la competencia y el resultado de ella; además, faculta y vigila la adecuación de los actos de autoridad al orden supra legal, porque (...) en un Estado de Derecho moderno, no basta la existencia de normas jurídicas por parte de quién detenta el poder político, sino que es necesario, para garantizar el imperio de la legalidad y estas normas deben contar con una serie de características en su origen y estructura... y que sean respetadas aplicando determinados criterios. ${ }^{72}$

\section{INTERPRETACIÓN DEL Art. 16 DEL CÓDIGO ORGÁNICO INTEGRAL PENAL, REFERENTE AL ÁMBITO DE APLICA- CIÓN TEMPORAL}

Antes de iniciar, es importante establecer que se entiende por interpretación jurídica, para Riccardo Guastini, la interpretación en estricto sentido se emplea para referirse a la atribución del significado a una formulación normativa en presencia de dudas o controversias en torno al campo de aplicación ${ }^{73}$. Esto nos lleva a considerar que únicamente se puede hacer una interpretación judicial cuando el texto de la norma que será objeto de interpretación es ambiguo.

Existen métodos de interpretación que pueden definirse como formas de proceder que permiten realizar una tesis razonable, a continuación mencionaremos cuatro métodos de interpretación:

72 Tamayo y Salmorán, Los publicistas, Digresión II. 214.

73 Guastini, R. (1999). Interpretar y Argumentar. 340. 


\begin{tabular}{|l|l|}
\hline \multicolumn{2}{|l|}{ Métodos de Interpretación de la Ley } \\
\hline $\begin{array}{l}\text { Método Gramatical: de acuerdo con } \\
\text { la semántica, en base a las reglas de } \\
\text { lenguaje, es decir, interpretación li- } \\
\text { teral de las disposiciones o normas. }\end{array}$ & $\begin{array}{l}\text { Método Sistemático: interpretación } \\
\text { de las disposiciones, en conjunto } \\
\text { den las demás, que conforman el or- } \\
\text { inserta. }\end{array}$ \\
\hline $\begin{array}{l}\text { Método Histórico: indagar sobre el jurico en el que está } \\
\text { espíritu con el cual se concibió a la la } \\
\text { norma. }\end{array}$ & $\begin{array}{l}\text { Método Teleológico: busca de ma- } \\
\text { nera preponderante la finalidad de } \\
\text { blecer el sentido y el alcance de la } \\
\text { misma. }\end{array}$ \\
\hline
\end{tabular}

Elaboración: Propia.

Fuente: Instituto de Investigaciones Jurídicas de la UNAM.

Después de lo establecido, podemos comenzar la interpretación del Art. 16 del Título V, del Código Orgánico Integral Penal, en él se establece el ámbito de aplicación temporal, expresa: los sujetos del proceso penal y las o los juzgadores observarán las siguientes reglas: 1) Toda infracción será juzgada y sancionada con arreglo a las leyes vigentes al momento de su comisión. 2) Se aplicará la ley penal posterior más benigna sin necesidad de petición, de preferencia sobre la ley penal vigente al tiempo de ser cometida la infracción o dictarse sentencia. 3) El ejercicio de la acción y las penas prescribirán de conformidad con este Código. 4) Las infracciones de agresión a un Estado, genocidio, lesa humanidad, crímenes de guerra, desaparición forzada de personas, peculado, cohecho, concusión, enriquecimiento ilícito y las acciones legales por daños ambientales son imprescriptibles tanto en la acción como en la pena. ${ }^{74}$

Para mejores resultados, analizaremos e interpretaremos a través del método sistemático cada una las reglas recogidas en el artículo mencionado, "toda infracción será juzgada y sancionada con arreglo a las leyes vigentes al momento de su comisión", esta regla en un lenguaje simple quiere decir que todo acto u omisión que este tipificado, será sancionado de acuerdo con las leyes vigentes. Aquello refleja que la norma tiene carácter irretroactivo, y cumple con el principio de legalidad, de aquí a

74 Código Orgánico Integral Penal, Registro Oficial $N^{\circ} 180,1^{\circ}$ de julio de 1895 , Última actualización 10 de febrero de 2014, Título V, Art. 16 inciso 1- 4. 
que esto sea aplicado, existe gran discusión. Sin embargo, considero que sería de gran utilidad que se establezca dentro del reglamento desde cuando una ley o norma entra en vigencia y cuando termina.

El ámbito de aplicación de la ley en materia penal, es uno de los cuatro efectos de la ley penal, además, se proyecta en el espacio, en el tiempo, en las personas y en la materia. "La temporalidad se refiere al tiempo, y cuando se relaciona lo temporal con la ley es sinónimo de vigencia"75

De acuerdo con los artículos 5,6 y 7 del Código Civil, "la promulgación de la ley deberá hacerse en el Registro Oficial"76, "la ley entrará en vigencia a partir de su promulgación en el Registro Oficial y por ende será obligatoria y se entenderá conocida de todos desde entonces", "la ley no dispone sino para lo venidero: no tiene efecto retroactivo; y en conflicto de una ley posterior con otra anterior".

Cabe mencionar, que existen casos en que la ley nace, pero no tiene vida de inmediato sino en un tiempo posterior, a este estado de suspensión temporal de la vigencia de la ley penal se lo conoce como vacatio legis. ${ }^{77}$

La segunda disposición establece que "se aplicará la ley penal posterior más benigna sin necesidad de petición, de preferencia sobre la ley penal vigente al tiempo de ser cometida la infracción o dictarse sentencia”, en otras palabras, se aplicará la ley posterior más afable o conveniente para el imputado, procurando hacerlo en el tiempo que fue cometido sobre la ley penal vigente.

La tercera disposición expresa, que "el ejercicio de la acción y las penas prescribirán de conformidad con este Código". Esta disposición tiene concordancia con la número cuatro ya que en ella se establecen los delitos tipificados, refiriéndose a las infracciones de agresión a un Estado, genocidio, lesa humanidad, crímenes de guerra, desaparición forzada de personas, peculado, cohecho, concusión, enriquecimiento ilícito y las acciones legales por daños ambientales son imprescriptibles tanto en la acción como en la pena.

75 Rosillo, V. (2017). Poder del Derecho, Quito. 12.

76 Código Civil Ecuatoriano, Registro Oficial N 46 del 10 de mayo del 2005, Artículo 5 , párrafo 1 .

77 Según el diccionario jurídico, vacatio legis, quiere decir exención de la ley que implica franqueza y libertad de la que alguien goza para eximirse de algún cargo u obligación. 
En la sentencia N. ${ }^{\circ}$ 066-15-SEP-CC, CASO N. ${ }^{\circ}$ 0377-12-EP, de la Corte Constitucional del Ecuador, se establece un claro ejemplo de infracción de agresión al Estado, este es el caso de PECULADO, como antecedentes se tiene que ${ }^{78}$ el doctor Rubén Darío Mogrovejo Romero, en calidad de director regional de la Procuraduría General del Estado, para las provincias de Loja y Zamora Chinchipe, compareció el 15 de febrero de 2012, ante la Segunda Sala de lo Penal de la Corte Nacional de Justicia, que dictó la sentencia el 07 de noviembre de 2011, dentro del recurso de casación N. 0854-2011.

Posteriormente, mediante providencia dictada el 17 de febrero de 2012, se resolvió remitir el expediente a la Corte Constitucional. El 01 de marzo de 2012, Secretaría General de la Corte Constitucional, de conformidad con lo establecido en el tercer inciso del cuarto artículo enumerado agregado a continuación del artículo 8 del Reglamento de Sustanciación de Procesos de Competencia de la Corte Constitucional, certificó que en referencia a la acción N. ${ }^{\circ}$ 0377-12-EP, no se ha presentado otra demanda con identidad de objeto y acción.

La Sala de Admisión de la Corte Constitucional, para el período de transición, conformada por los jueces constitucionales Ruth Seni Pinoargote, Edgar Zárate Zárate y Hernando Morales Vinueza, el 07 de mayo de 2012 admitió a trámite la acción extraordinaria de protección N. ${ }^{\circ}$ 0377-12-EP.

La Secretaría General de la Corte Constitucional, para el período de transición, al sorteo realizado por el Pleno del Organismo en sesión extraordinaria del 05 de julio de 2012, remitió la acción extraordinaria de protección N. $^{\circ}$ 0377-12-EP a la jueza constitucional

Nina Pacari Vega, quien avocó conocimiento de la causa el 21 de agosto de 2012, en calidad de jueza; al aplicar los artículos 25 a 27 del Régimen de Transición de la Constitución de la República, el 6 de noviembre de 2012 fueron posesionados los jueces de la primera Corte Constitucional. En tal virtud, el Pleno del Organismo procedió al sorteo de causas efectuado el 03 de enero de 2013. De conformidad con dicho sorteo, el secretario general remitió el expediente a la jueza constitucional, Wendy Molina Andrade, quien avocó conocimiento de la presente causa.

78 Corte Constitucional Del Ecuador, Sentencia N. ${ }^{\circ}$ 066-15-SEP-CC, CASO N. ${ }^{\circ} 0377-$ 12-EP, Párrafo del 1-5, 2015. 


\section{CONSIDERACIONES Y FUNDAMENTOS DE LA CORTE CONSTITUCIONAL}

\section{Competencia}

La Corte Constitucional es competente para conocer y resolver sobre las acciones extraordinarias de protección en contra de sentencias, autos definitivos y resoluciones con fuerza de sentencia, de conformidad con lo previsto en los artículos 94 y 437 de la Constitución de la República, en concordancia con los artículos 63 y 191 numeral 2 literal d de la Ley Orgánica de Garantías Jurisdiccionales y Control Constitucional, y de acuerdo con el artículo 3 numeral 8 literal b, y tercer inciso del artículo 35 del Reglamento de Sustanciación de Procesos de Competencia de la Corte Constitucional.

Desarrollo del problema jurídico la sentencia dictada por la Segunda Sala de lo Penal de la Corte Nacional de Justicia, dentro del recurso de casación $\mathrm{N} .^{\circ}$ 0854-2011, ¿̇vulneró el derecho a la seguridad jurídica, previsto en el artículo 82 de la Constitución «la República?

Previo al análisis del problema jurídico planteado, la Corte Constitucional debe puntualizar que no es materia de su competencia analizar si las autoridades judiciales, dentro de sus fallos o resoluciones, aplicaron incorrectamente determinados preceptos legales o, en este caso, disposiciones generales y obligatorias, pues esa atribución es propia de la justicia ordinaria, salvo que dicha inobservancia haga referencia a una norma constitucional o vulnere de manera directa un derecho consagrado en la Carta suprema, en cuyo caso será competencia de esta Corte pronunciarse al respecto. ${ }^{79}$ Ahora bien, a base de este criterio jurisprudencial, propio de la bidimensionalidad en la que se puede incurrir a la hora de analizar derechos como el debido proceso en el cumplimiento de normas o la seguridad jurídica, cabe señalar que en el presente caso, según lo ha manifestado el accionante, se habría vulnerado el derecho a la seguridad jurídica en el momento en que, dentro de la sentencia impugnada, se aplicó con efectos retroactivos la resolución general y obligatoria s/n dictada el 12 de marzo de 2010, por

79 Corte Constitucional Del Ecuador, sentencia No. 020- 13-SEP-CC, caso N.0563-12-EP 
el Pleno de la Corte Nacional de Justicia, en uso de su facultad prevista en el artículo 180 numeral 6 del Código Orgánico de la Función Judicial.

Por consiguiente, dada la connotación y alcance de los hechos denunciados, en donde aparentemente se habría afectado un principio fundamental en la vigencia y aplicación de las normas como es el "principio de irretroactividad", y con ello, una evidente afectación del derecho a la seguridad jurídica consagrado en el artículo 82 de la Constitución de la República, esta Corte, al reconocer la connotación constitucional del presente caso, considera indispensable analizar dicha alegación a través del presente problema jurídico, con el ánimo de identificar la vulneración o no de este derecho constitucional.

La Norma Suprema consagra el derecho a la seguridad jurídica, en función del cual se pretende garantizar la sujeción de todos los poderes del Estado a la Constitución y a la ley, a través de la existencia de normas jurídicas previas, claras y públicas, las mismas que deben ser debidamente aplicadas por las autoridades correspondientes.

La seguridad jurídica tiene como fundamento esencial la existencia de un ordenamiento jurídico previamente establecido, cuya observancia y correcta aplicación debe darse en los casos concretos por parte de los poderes públicos, de tal manera que los ciudadanos tengan certeza respecto a la aplicación del derecho vigente, y en cuanto al reconocimiento y previsibilidad de las situaciones jurídicas. ${ }^{80}$

Dentro del caso subexamine, el representante de la Procuraduría General del Estado manifiesta que se vulneró el derecho a la seguridad jurídica en vista que se aplicó de forma retroactiva la resolución general y obligatoria s/n dictada el 12 de marzo de 2010 por el Pleno de la Corte Nacional de Justicia, cuando claramente, en su artículo 3 se establece que: "Las normas previstas en esta resolución, regirán para el futuro y por tanto se aplicarán únicamente para las causas que se iniciaren a partir de su promulgación"; y que a la fecha en que se suscitaron los hechos y desarrollaron las etapas procesales que provocaron una sentencia condenatoria por el delito de peculado en contra del señor Segundo Aurelio Mejía Bermeo, aún no se encontraba vigente la resolución del Pleno de la Corte Nacional de Justicia, por lo que no podía aplicarse dicha resolución.

80 Corte Constitucional del Ecuador, sentencia No. 067-13-SEP-CC, caso N. 2172-11-EP. 
Ahora bien, frente a los argumentos expuestos por el accionante, y una vez revisada la sentencia junto con los argumentos desarrollados en esta, se puede determinar que contrario a lo señalado por el accionante, los jueces de casación sustentan su fallo sin remitirse de manera expresa a la resolución general y obligatoria dictada por el Pleno de la Corte Nacional de Justicia y sin aplicar su articulado dentro de la argumentación del fallo.

Es así que la decisión adoptada por la Sala de Casación es sustentada a base de tres criterios principales, los cuales serán referidos a continuación: En primer lugar, los jueces de casación señalan que la sentencia dictada por los jueces de la Primera Sala de la Corte Provincial de Justicia de Zamora ha violado la ley, pues ha efectuado una incorrecta aplicación de la ley sustantiva y procesal, y ha adecuado incorrectamente la conducta del acusado en la hipótesis típica prevista en el artículo 257 del Código Penal, por falta del informe de Contraloría General del Estado, que contenga los indicios de responsabilidad, como es el criterio de las Salas penales de esta Corte.

Como segundo punto señalan:

"[...] la prueba que el acusado debe ser reputado como autor del grave delito que se le imputa no fue presentada en la audiencia del juicio, conforme al Art. 79 del Código de Procedimiento Penal [...]"; "La prueba tanto de la materialidad del delito, como de la responsabilidad y culpabilidad del imputado no ha sido producida cumpliendo los principios propios del modelo acusatorio, esto es, de manera oral y pública, ejerciendo las partes el derecho al contradictorio (sic), y respetando los principios de la continuidad o concentración, así como cumpliendo con el principio de la inmediación de la prueba con el juez de la sentencia. La materialidad del delito así como la culpabilidad del acusado, no se encuentran debidamente probadas, como se ha analizado en esta sentencia".

Finalmente, como tercer argumento, manifiestan que [...] la Sala Penal no ha hecho una correcta adecuación típica de la conducta sancionable, por lo que no ha lugar las alegaciones del Dr. Washington Pesantes Muñoz, Fiscal General del Estado, por cuanto se contradice en otro dictamen, concretamente en el proceso penal 395/2010, radicado en la Primera Sala Penal de esta Corte, estableció que para cometer delitos de peculado se necesita con (sic) la Contraloría haya determinado indicios de responsabilidad penal, por lo que se abstuvo de acusar, 
pese a la sentencia condenatoria de los recurrentes, para solicitar que se corrija la sentencia recurrida por contravenir expresamente a la ley, y existir una errónea interpretación de las normas acusadas.

La Corte tomó la decisión de:

1. Declarar que no existe vulneración de derechos constitucionales,

2. Negar la acción extraordinaria de protección planteada,

3. Notifíquese, publíquese y cúmplase. ${ }^{81}$

En esta causa, la parte accionante demanda, el principio fundamental en la vigencia y aplicación de las normas como es el "principio de irretroactividad", y con ello, una evidente afectación del derecho a la seguridad jurídica consagrado en el artículo 82 de la Constitución de la República.

En ello se resume todo lo referente a lo expuesto dentro de este artículo, al esperar que sea de utilidad para los entendidos de la materia y la promoción de su divulgación dentro del ámbito profesional del Derecho.

\section{CONCLUSIONES}

De lo expuesto en un principio, se infiere que la irretroactividad de la ley desfavorable y retroactividad de la ley más benigna, necesitan estar en constante coordinación, y a pesar que la prohibición de retroactividad sugiere una sucesión de leyes, en realidad aquello no sucede. También rige el principio de irretroactividad cuando la ley crea un delito, en otras palabras criminaliza un hecho, no contemplado anteriormente en ningún ordenamiento jurídico.

Se debe constatar que en la doctrina y jurisprudencia forma parte del principio de legalidad penal la exigencia que las leyes penales sean irretroactivas, que se trate de una ley previa, escrita, estricta y segura. En realidad se trata de una forma de proceder que se queda en la superficie del problema que no va al fondo del asunto.

81 Corte Constitucional Del Ecuador, Sentencia N. ${ }^{\circ}$ 066-15-SEP-CC, CASO N. ${ }^{\circ} 0377-$ 12-EP, Párrafo 9, 2015. 
Los derechos adquiridos a diferencia de las meras expectativas, no son afectados por la ley posterior, las reglas de la ley sobre efecto retroactivo siguen la doctrina de los derechos adquiridos para resolver los conflictos de retroactividad de la ley.

Las reglas particulares de la ley; sin embargo, resuelven conflictos de leyes en el tiempo, mediante criterios análogos a los de la doctrina de la relación jurídica. En la generalidad de los casos, la ley hace la distinción entre la Constitución, el momento en que produce sus efectos y finalmente la extinción de la relación jurídica. La ley establece de modo reiterado que la Constitución se rige por la ley vigente al momento de producirse; que los efectos se rigen por la ley nueva desde su publicación y que la extinción se rige por la ley vigente al momento en que sucede.

La sociedad debe encargarse de poner por lo alto los valores fundamentales, solo así viviremos en "un mundo donde el individuo no se obliga por sus compromisos sino en la medida en que le convenga es un mundo donde la sociedad solo puede volverse cada vez más violenta y cada vez más policiaca; es un mundo donde los débiles, que pagan el precio más alto, dejan de concederle el menor crédito a la palabra política y el menor valor a las leyes", como dice Alain Supiot.

\section{REFERENCIAS BIBLIOGRÁFICAS}

Anchonda, V. (2013). Métodos de interpretación jurídica, Instituto de investigaciones jurídicas de la UNAM.

Aranda, D. (2003). Derecho Penal, Parte general (conceptos, principios y fundamentos del Derecho Penal mexicano, conforme a la teoría del delito funcionalista social), UNAM, México..

Arroyo, L. (1983). El Principio de Determinación del Hecho Punible en la Doctrina del Tribunal Constitucional, Madrid.

Bacigalupo, E. (1999). Principios Constitucionales de Derecho Penal. Buenos Aires, 1999.

Barros, E. (1995). Vigencia de la ley. Efectos de la ley en el tiempo, Universidad de Chile. 
Calderón, G. (2000). El fundamento del principio de irretroactividad de la ley penal, Revista de Derecho de la Universidad Católica de Valparaíso, Chile.

Carlos, D. (2012). Retroactividad e Irretroactividad, Los tiempos.

Carvajal, F. (2012). Crimen de agresión en Derecho Penal Internacional. Responsabilidad del Individuo por acto de Estado, Publidisa.

Cobo del Rosal, T. y Vives Antón, M. (1999). Comentario al art. 2 del Código Penal, en Comentarios al Código Penal (Dir. por Manuel Cobo del Rosal, Ed. Edersa, Madrid)

Cobo del Rosal, T. y Vives Antón, M. (1999). Comentario al art. 2 del Código Penal, en Comentarios al Código Penal (Dir. por Manuel Cobo del Rosal, Ed. Edersa, Madrid)

Cobo del Rosal, T. y Boix Reig, J. (1982). Garantías Constitucionales del Derecho Sancionador, Madrid.

Donde, J. (2012). Principio de Legalidad Penal. Perspectivas del Derecho Nacional e Internacional, México, Porrúa.

Guevara, B. (2013). La prohibición de la aplicación retroactiva de la ley, Instituto de investigaciones jurídicas de la UNAM.

Gómes, L. (2001). El Principio de Legalidad y sus Garantías Mínimas: Una Contribución al Estudio de la Garantía de la "Lex Populi", Universidad de Castilla- La Mancha.

Guastini, R. (1999). Interpretar y Argumentar.

Habermans, J. (2009). Facticidad y validez: sobre el derecho y el estado democrático de Derecho, Universidad Johann Wolfgang Goethe.

Islas Montes, R. (2009). Sobre el Principio de Legalidad, Anuario de Derecho Constitucional latinoamericano.

Kelsen, H. (1985). Teoría General de las Normas, Editorial Trillas, Praga

Kelsen, H. (2007). Teoría general del Derecho y del Estado. 
Kelsen, H. (2007). Teoría para el Derecho, México.

Kelsen, H. (2005). Validez y Eficacia del Derecho, Editorial Astrea.

Lamarca, C. (2012). Principio de Legalidad Penal, Eunomía. Revista en Cultura de la Legalidad. Universidad Carlos III de Madrid.

Laporta, F. (2004). Imperio de la ley. Reflexiones sobre un punto de partida de Elías Díaz, en Carbonell, M., Orozco, W. y Vásquez, R., coord., supra nota 34 .

Maier, J. (2003). Derecho Procesal II, Parte General. Sujetos Procesales, Buenos Aires, Editores del Puerto.

Montesquieu (1992). O espírito das leis, trad. de Pedro Vieira Mota, $2^{a}$ ed., São Paulo: Saravia, especialmente "Libro Décimo Primeiro".

Palladino, P. (2014). La Ley Penal en el Tiempo, Madrid - España.

Rodríguez, A. (2000). La aplicación de la ley penal más favorable, Puerto Rico.

Rosillo, V. (2017). Poder del Derecho, Quito.

Ruiz, L. (2011). El Principio de Irretroactividad de la Ley Penal en la Doctrina y la Jurisprudencia, Derecho Penal, Universidad de Extremadura.

Saavedra, J. (1994). Aplicación Retroactiva de la Ley Penal, Anuncio Jurídico. Nueva Serie.

Suárez Collía, J.M. (2005). En La retroactividad: Normas jurídicas retroactivas e irretroactivas. Edita Centro de Estudios Ramón Areces. Madrid.

Tamayo, R. y Salmorán, R. (2015). Los publicistas medievales y la formación de la tradición política de occidente, México, UNAM.

Ulloa, A. (2013). Principio de Legalidad y Derecho Penal Contemporáneo, Revista de Derecho, Ecuador.

Ulloa, A. (2013). Principio de Legalidad y Derecho Penal Contemporáneo, Revista de Derecho, Ecuador. 
Universidad Interamericana para el Desarrollo. (2011). Ámbito de validez del Derecho Penal, México.

Verdera Izquierdo, B. (2006). En La irretroactividad: Problemática general. Editorial Dykinson. Madrid.

\section{Base Legal}

Código Organico Integral Penal, Registro Oficial 180 del $1^{\circ}$ de julio de 1895, Última Edición 10 de febrero de 2014.

Constitución de la República del Ecuador, Registro Oficial 449 del 20 de octubre del 2008, Artículo 137, Párrafo 3.

Código Civil Ecuatoriano, Registro Oficial N 46 del 10 de mayo del 2005, Artículo 7, párrafo 3.

Declaración Universal de los Derechos Humanos, Registro Oficial 10 de diciembre de 1948, Resolución 217, Artículo 11 inciso 2. 2015.

Código Orgánico Integral Penal, Registro Oficial $N^{\circ} 180,1^{\circ}$ de julio de 1895, Última actualización 10 de febrero de 2014, Título V, Art. 16 inciso 1- 4.

Código Civil Ecuatoriano, Registro Oficial N 46 del 10 de mayo del 2005, Artículo 5, párrafo 1.

Corte Constitucional del Ecuador, Sentencia N. ${ }^{\circ}$ 066-15-SEP-CC, CASO N. ${ }^{\circ}$ 0377-12-EP, Párrafo del 1-5, 2015. 
Recibido: 04/08/2017

Aceptado: 23/05/2018

Renata Melissa Yunda López: Investigadora Jurídica Blue Wave Ybstelcom S.A.

Correo electrónico: renimelyunda@gmail.com 